University of Nebraska - Lincoln

DigitalCommons@University of Nebraska - Lincoln

Management Department Faculty Publications

Management Department

1989

\title{
Framing the Problem and Making Decisions: The Facts are Not Enough
}

\author{
Dennis Duchon \\ University of Nebraska-Lincoln, dduchon2@unl.edu \\ Kenneth Dunegan \\ Cleveland State University \\ Sidney L. Barton \\ University of Cincinnati
}

Follow this and additional works at: https://digitalcommons.unl.edu/managementfacpub

Part of the Management Sciences and Quantitative Methods Commons

Duchon, Dennis; Dunegan, Kenneth; and Barton, Sidney L., "Framing the Problem and Making Decisions: The Facts are Not Enough" (1989). Management Department Faculty Publications. 89.

https://digitalcommons.unl.edu/managementfacpub/89

This Article is brought to you for free and open access by the Management Department at DigitalCommons@University of Nebraska - Lincoln. It has been accepted for inclusion in Management Department Faculty Publications by an authorized administrator of DigitalCommons@University of Nebraska - Lincoln. 


\title{
Framing the Problem and Making Decisions: The Facts are Not Enough
}

\author{
DENNIS DUCHON, KENNETH J. DUNEGAN, AND SIDNEY L. BARTON
}

\begin{abstract}
One hundred ten engineers, scientists, and managers in a high-technology international engineering firm took part in an experiment that assessed the effect of framing on an $R \& D$ financial allocation decision. Subtle changes in frame of reference are found to have a powerful effect on decisions and perception of risk. R\&D management implications are discussed.
\end{abstract}

\section{INTRODUCTION}

$\mathrm{C}$ HOICES and the explanation of choices made in R\&D management-why certain projects are selected, why they are funded at a given level, and why they are terminated-are often assumed to have a rational basis. Although what exactly constitutes that rational basis has been much debated, there is general agreement that rational choice should satisfy some elementary requirements of consistency and coherence [7].

Yet Tversky and Kahneman [7] have demonstrated that people often systematically violate requirements of consistency and coherence. These violations come as a result of decision makers adopting different frames for their decisions. Frames refer to the decision maker's conception of the acts, outcomes, and contingencies associated with a particular choice. The adoption of a given frame depends not only on the personal characteristics of the decision maker, but also on the formulation of the problem itself. Thus, objective facts can take on different meaning when framed differently. Specifically, different formulations of a decision problem using the same objective facts can lead to different decisions. Consider, for example, a financial allocation decision for a project that is going badly. Does the project manager "see" the project's future potential, or does he or she "see" the difficulties. Whether or not the project continues to be funded will depend in part on how it is seen, that is, in how the objective facts are framed or presented.

The present experiment manipulates very subtly the framing of an R\&D financial allocation decision. Framing has been shown to influence the decisions of student subjects who work at abstract decision-making tasks [5]. This study extends the examination of framing effects by using experienced organizational decision makers who make a decision that is apropos of their work life. Framing would indeed be a potent factor in R\&D management decision making if engineers, scientists,

Manuscript received August 14, 1987; revised May 19, 1988. The review of this paper was arranged by Department Editor P. H. Birnbaum.

D. Duchon is with the University of Texas at San Antonio, San Antonio, $\mathrm{TX}$

K. J. Dunegan is with Cleveland State University, Cleveland, $\mathrm{OH}$

S. L. Barton is with the University of Cincinnati, Cincinnati, OH

IEEE Log Number 8823939. and engineering managers are subject to its influence. The data analysis reported below even takes into account the degree to which subjects see themselves as rational versus intuitive decision makers. This self-perception thus allows us to take into account a personal characteristic which might lead to differences in choice [7].

$$
\text { Method }
$$

\section{Subjects}

One hundred ten professional employees of a high-technology international engineering firm took part in the experiment. Fifty-two of the subjects hold a bachelor's degree, 51 hold a master's degree, and seven hold a Ph.D. Subjects represent both managerial and technical personnel, although 76 percent of the sample are engineers or scientists. The sample is predominately male ( 98 males, 8 females, and 4 subjects for whom gender data are not available). The sample on average is 33.8 years of age, has 5.2 years of experience with the firm, and supervises 2.7 people. Subjects also represent different nationalities including English, Japanese, French, and German, although most of the subjects ( 69 percent) are citizens of the United States.

\section{Procedure and Manipulation}

Subjects read the following financial allocation scenario:

As R\&D manager, one of your project teams has come to you requesting an additional $\$ 100000$ in funds for a project you instituted several months ago. The project is already behind schedule and over budget, but the team still believes it can be successfully completed. You currently have $\$ 500000$ remaining in your budget unallocated, but which must carry you for the rest of the fiscal year. Lowering the balance by an additional $\$ 100000$ might jeopardize flexibility to respond to other opportunities.

Evaluating the situation, you believe there is a fair chance the project will not succeed, in which case the additional funding would be lost; if successful, however, the money would be well spent ...

The last sentence of the scenario for subjects randomly assigned to one frame (Frame 1) condition read: "Of the projects undertaken by the team, 30 of the last 50 have been successful." The last sentence of the scenario for subjects randomly assigned to the other frame (Frame 2) condition read: "Of the projects undertaken by this team, 20 of the last 50 have been unsuccessful." Note that, statistically, the team's success ratio is 60 percent in both cases. 
The wording for the framing conditions in both cases was adapted from Davis and Bobko [2]. Note that the framing conditions are subtle but offer different reference points for the decision problem. Furthermore, as an assessment of the decision problem's face validity, three members of the company's top management reviewed the scenario and unanimously agreed it represented a decision the subjects would understand and may reasonably encounter on their jobs.

\section{Covariate}

Because the issue of "rational" choice is important, and because the sample is assumed to have a "rational" disposition due to training and experience, an assessment of the subjects' perception of their disposition toward rational decision making was made. Lee [5] has argued that it is useful to describe people along a continuum of rationality; therefore, subjects gave a self-assessment of themselves as either rational or intuitive decision makers by responding on a seven-point scale to a question which asked, "In general, do you consider yourself to be ..." The seven-point scale was anchored by $1=$ a rational decision maker and $7=$ an intuitive decision maker. The scale anchors were chosen to reflect fundamentally different decision-making approaches: a rational approach (i.e., systematic, objective, logical) and an intuitive approach (i.e., attaining cognition without evident systematic thought). The term "irrational" is not an appropriate opposite anchor for "rational" because it has a strong pejorative connotation. Intuitive, on the other hand, does suggest a process very different from rational, but one which does not carry an undesirable connotation.

The average response was 3.3 (i.e., on the "rational" side of the scale). The standard deviation (SD) was 1.44, and responses ranged from 1 to 7 . This self-perception report was used as a covariate in portions of the analyses to control for disposition toward rationality which may have altered responses independent of framing conditions.

\section{Dependent Measures}

After reading the scenario, subjects indicated the likelihood they would fund the request by selecting from alternatives on the following five-point scale:

\begin{tabular}{ccccc}
\hline \multirow{2}{*}{ Reject } & $\begin{array}{c}\text { Lean Toward } \\
\text { Rejecting }\end{array}$ & Uncertain & $\begin{array}{c}\text { Lean Toward } \\
\text { Funding }\end{array}$ & Fund \\
\cline { 2 - 3 } & 2 & 3 & 4 & 5 \\
\hline
\end{tabular}

In addition to indicating whether or not they would fund the project, subjects were asked to indicate the level of risk they believed was associated with providing the additional funding. If framing alters the psychology of decision making by altering perception of the problem, then it seems likely that framing is also altering the decision maker's perception of the risk she or he is taking when making the decision. Rational decision makers are not people who take chances just for the thrill of it. Rather, rational decision makers are likely risk avoiders or risk minimizers who make decisions consistent with their perception of risk in the decision-making episode. Therefore,
TABLE I

INCLINATION TO GRANT ADDITIONAL FUNDING BY FRAME CONDITIONS $^{1}$

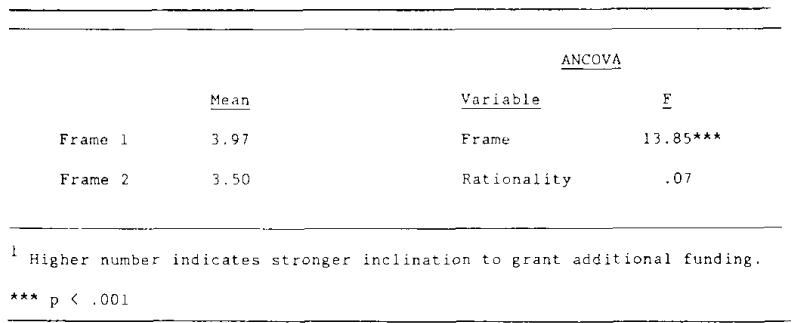

as framing changes perceptions of the decision-making problem, so too will it change perceptions of the risk in the problem. Subjects responded to a scale item in which they indicated the degree of risk they believed associated with additional funding: 1 = No risk, $2=$ Some risk, $3=$ Normal risk, 4 = Considerable risk, $5=$ Too risky.

\section{RESULTS}

\section{Data Analysis}

Table I reports the inclination that subjects would fund the request in the decision scenario. Subjects in Frame 1 indicate a stronger inclination to fund the project than subjects in Frame 2 (average response Frame 1, 3.97 versus 3.50 for Frame 2). When inclination to fund the request is used as the dependent variable in a one-way analysis of covariance (with degree of rationality used as the covariate), significant differences are indicated in the dependent variable $\left(F=1.95, p<0.05, R^{2}\right.$ $=0.19$ ). Examination of the variables in the model indicate a significant effect for framing ( $F=13.85, p<0.001)$, but not for the covariate ( $F=0.07$, ns). Thus, even when controlling for possible differences in degree of rationality for presumably very "rational" decision makers, framing effects are found. Therefore, framing and not degree of rationality accounts for differences in behavior in this study.

Framing is also related to perception of risk. When asked to report the degree of risk they perceive in the decision scenario, the average response of subjects in Frame 1 is 3.01 ( $\mathrm{SD}=$ 0.68 ), while the average response of subjects in Frame 2 is $3.34(\mathrm{SD}=0.64)$. These responses are significantly different ( $t=2.54, p<0.05$ ). Thus, the subtle frame of reference manipulation affected perceptions of objective risk. It can also be noted that the correlation between perception of risk and inclination to fund the request is $-0.21(p<0.05)$. That is, subjects who see greater risk in the scenario are less likely to fund the request. Thus, framing not only changed the perception of objective risk in the project, but also led to differences in an inclination to fund the project.

\section{DISCUSSION}

This paper reports the results of an experiment in which a sample of experienced engineers, scientists, and managerspeople who would be expected to be objective decision makers, and who report themselves to be rational decision makers-are influenced by very subtle informational cues. These subtle cues did not alter the object facts in an R\&D financial allocation decision, but they did apparently alter the 
decision maker's reference point. The cues also apparently altered the degree of risk perceived in the decision scenario. As a result, the decision makers exposed to different frames made different decisions, and reported perceiving different levels of risk in the decision episode.

The data presented in this paper clearly demonstrate that knowing "just the facts" in a decision-making situation is insufficient for predicting choice. Understanding choice requires an understanding of the decision maker's frame of reference. Different frames of reference can lead to different choices because different reference frames lead to different interpretations of what the facts mean. This by no means implies that the decision makers in this experiment acted "irrationally." The decision makers in this experiment were quite "rational" from at least one view of consistency because those perceiving the decision to continue funding to be a risky one were less inclined to fund than those perceiving the decision to be less risky. Yet those choosing either to fund or not to fund were operating with the same objective facts. That is, the same facts still lead to inconsistent choices. This suggests that it is unwise to assume that even experienced engineers, scientists, and managers can reliably achieve a unitary interpretation of the facts.

Several explanations have been offered for why framing the facts in different ways can lead to different decisions. Kahneman and Tversky's [4] prospect theory posits that framing differences lead to systematic differences in the way decision makers process and edit information. These processing and editing differences lead to different choices. Arkes and Blumer [1] have elaborated on certain aspects of prospect theory by arguing that decision makers in a situation similar to the one captured in our decision scenario are responding to sunk costs. That is, the psychological weight of the commitment of money, time, and effort that goes into a decision represent costs that are sunk into the decision, costs which are difficult, even impossible, to ignore when later the decision appears to have been a bad one. Rather than reversing oneself, Arkes and Blumer [1] contend that the decision maker does not want to appear wasteful of the money, time, and effort already spent; and so she or he will continue to fund a project, even though objectively such funding may not be defensible. These explanations are valuable, but the mechanisms of the psychology of decision making are imperfectly understood and future research is needed, especially research focusing on real decision makers, not only to explore the mechanisms of framing but also to explore the kinds of reference points decision makers adopt.

Although the underlying mechanisms of framing are not perfectly understood, several implications for R\&D management can be drawn from this study. First, managers need to realize that the "facts" do not speak for themselves. Rather, the facts are interpreted in terms of a frame of reference. Over the course of time the norms and social expectations within an R\&D group can lead to a common set of assumptions about "what we do" and "what we are." In a sense the group adopts a common frame within which all "facts" are interpreted. While this process makes certain kinds of communication easier, it also leads to intellectual blindspots. Because of the common frame of reference, the group tends to identify and solve the same problems over and over. And there are never any questions or doubts because all agree on what "facts" mean and the "facts" tell us "we're doing the only thing we can do." Janis [3], for example, has noted how this can happen to highly cohesive decision-making groups. To prevent such a problem, management needs to consider problems from different points of view or different frames. Multiple frames can ensure a less biased view of the "facts" associated with a problem and, therefore, better decisions.

Encouraging the development of different frames of reference can also, however, lead to conflict. The conflict will not be about "facts," but rather about "interpretation of facts." Yet, such conflict can be resolved by having people identify the frame of reference they use in understanding the facts. Also, conflict can be defused by reminding people that multiple reference points are valuable and useful if the organization is to remain vital.

Understanding reference points and risk taking can also help managers in the organization. The data in this study suggest that describing a project (even a troubled project) in positive and hopeful terms (Frame 1) lessens the perceived risk associated with that project. Managers can thus generate support by using framing to reduce the perceived risks associated with their project.

Frame of reference is an important concept to understand, especially for people accustomed to dealing with facts. In addition to the facts, the effective $R \& D$ manager will be sensitive to interpretational differences among people, and be aware of how easily frame of reference can be influenced.

\section{ACKNOWLEDGMENT}

The authors wish to thank $J$. Meredith and three anonymous reviewers for their helpful comments on an earlier draft of this paper.

\section{REFERENCES}

[1] H. R. Arkes and C. Blumer, "The psychology of sunk cost," Org. Behavior and Human Dec. Processes, vol. 35, pp. 124-140, 1985.

[2] M. Davis and P. Bobko, "Contextual effects on escalation processes in public section decision making," Org. Behavior and Human Dec. Processes, vol. 37, pp. 121-138, 1986.

[3] I. L. Janis, Victims of Groupthink. Boston, MA: Houghton Mifflin, 1972.

[4] D. Kahneman and A. Tversky, "Prospect theory: An analysis of revision under risk," Econometrica, vol. 47, no. 2, pp. 263-291, 1979.

[5] W. Lee, Decision Theory and Human Behavior. New York: Wiley, 1971.

[6] M. Mowen and J. Mowen, "An empirical examination of the biasing effects of framing on business decisions," Decision Sciences, vol. 17, pp. 596-602, 1986.

[7] A. Tversky and D. Kahneman, "The framing of decisions and the psychology of choice," Management Sci., vol. 211, pp. 453-458, 1981. 